February 2005 • NREL/CP-520-37391

\title{
Enhanced Adhesion of EVA Laminates to Primed Glass Substrates Subjected to Damp Heat Exposure
}

F.J. Pern and G.J. Jorgensen

Prepared for the $31^{\text {st }}$ IEEE Photovoltaics Specialists Conference and Exhibition

Lake Buena Vista, Florida

January 3-7, 2005
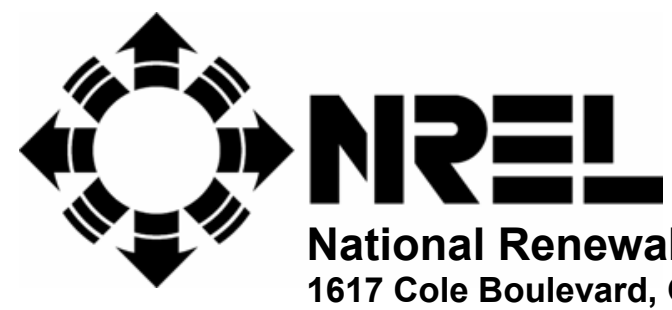

National Renewable Energy Laboratory 1617 Cole Boulevard, Golden, Colorado 80401-3393 303-275-3000 • www.nrel.gov

Operated for the U.S. Department of Energy

Office of Energy Efficiency and Renewable Energy

by Midwest Research Institute $\bullet$ Battelle

Contract No. DE-AC36-99-G010337 


\section{NOTICE}

The submitted manuscript has been offered by an employee of the Midwest Research Institute (MRI), a contractor of the US Government under Contract No. DE-AC36-99G010337. Accordingly, the US Government and MRI retain a nonexclusive royalty-free license to publish or reproduce the published form of this contribution, or allow others to do so, for US Government purposes.

This report was prepared as an account of work sponsored by an agency of the United States government. Neither the United States government nor any agency thereof, nor any of their employees, makes any warranty, express or implied, or assumes any legal liability or responsibility for the accuracy, completeness, or usefulness of any information, apparatus, product, or process disclosed, or represents that its use would not infringe privately owned rights. Reference herein to any specific commercial product, process, or service by trade name, trademark, manufacturer, or otherwise does not necessarily constitute or imply its endorsement, recommendation, or favoring by the United States government or any agency thereof. The views and opinions of authors expressed herein do not necessarily state or reflect those of the United States government or any agency thereof.

Available electronically at http://www.osti.gov/bridge

Available for a processing fee to U.S. Department of Energy and its contractors, in paper, from:

U.S. Department of Energy

Office of Scientific and Technical Information

P.O. Box 62

Oak Ridge, TN 37831-0062

phone: 865.576 .8401

fax: 865.576.5728

email: mailto:reports@adonis.osti.gov

Available for sale to the public, in paper, from:

U.S. Department of Commerce

National Technical Information Service

5285 Port Royal Road

Springfield, VA 22161

phone: 800.553 .6847

fax: 703.605.6900

email: orders@ntis.fedworld.gov

online ordering: http://www.ntis.gov/ordering.htm 


\title{
ENHANCED ADHESION OF EVA LAMINATES TO PRIMED GLASS SUBSTRATES SUBJECTED TO DAMP HEAT EXPOSURE
}

\author{
F. J. Pern and G. J. Jorgensen \\ National Center for Photovoltaics \\ National Renewable Energy Laboratory \\ 1617 Cole Blvd., Golden, CO 80401
}

\begin{abstract}
We investigated the effectiveness of glass-surface priming to promote enhanced adhesion of EVA laminates during damp-heat exposure at $85^{\circ} \mathrm{C}$ and $85 \%$ relative humidity. The primary objective was to develop advanced encapsulant formulations by incorporation of various primer formulations that exhibit improved adhesion during damp-heat exposure. Several primer formulations were identified that greatly enhanced the EVA adhesion strength, including to the extent that peeling could not be initiated, even for the laminates of the glass substrate/fastcure EVA15295P/TPE backsheet (a Tedlar/ polyester/EVA tri-laminate) that were exposed in a damp-heat test chamber for more than $750 \mathrm{~h}$. The results show that a synergistic increase in the interfacial hydrophobicity, siloxane density, and cross-linking density are the key attributes to the improvement in the EVA adhesion strength.
\end{abstract}

\section{INTRODUCTION}

A critical issue in the long-term performance and reliability of PV modules [1], especially polycrystalline thinfilm modules [2] without frames and edge seals, is their resistance to moisture ingress. Passing the stringent damp-heat test at $85^{\circ} \mathrm{C}$ and $85 \%$ relative humidity $(\mathrm{RH})$ for $1000 \mathrm{~h}$ in the IEEE 1262 qualification test has proven difficult for many thin-film modules; delaminations of thinfilm solar cells, encapsulants, and/or backsheets have occurred. Five workshops have been held in the last few years to discuss and address the related moisture ingress and thin-film reliability issues [3-7]. Moisture vapor is well known to cause multiple problems on polymers as well as adhesive joints. Upon absorption of water, a polymer may become swollen, plasticized, and/or hydrolyzed if its component bonding is susceptible to hydrolysis (such as the ester linkage in polyester at high $\mathrm{pH}$ ). Generally, water can decrease the glass transition temperature, tensile strength, and modulus of a polymer, but increase its elongation at break. These properties can recover fully when the polymer is dried, unless irreversible hydrolysis has occurred. The deterioration of a polymer is greater and faster in higher relative humidity and temperature than in liquid water, because permeation of the vapor is more rapid [7]. The moisture ingress properties of a polymer can be assessed by its permeability coefficient $(P)$ and the diffusion constant (D) of water [8,9]. For example, values of $P$ for more water-resistant polyisobutylene (PIB), phenolic, and epoxy polymers at $25^{\circ} \mathrm{C}$ are $7-22,166$, and $10-40 \times 10^{-9}\left(\mathrm{~cm}^{3}\right.$ (STP) $\left.\mathrm{cm}\right) /\left(\mathrm{cm}^{2} \mathrm{~s} \mathrm{~cm} \mathrm{Hg}\right)$, respectively. For less water-resistant polyvinyl acetate at $40^{\circ} \mathrm{C}, \mathrm{P}$ is 600 $\times 10^{-9}\left(\mathrm{~cm}^{3}(\mathrm{STP}) \mathrm{cm}\right) /\left(\mathrm{cm}^{2} \mathrm{~s} \mathrm{~cm} \mathrm{Hg}\right)$. The corresponding $D$ values for the last three polymers (N/A for PIB) are 0.2$10,2-8$, and $150 \times 10^{-9} \mathrm{~m}^{2} / \mathrm{s}$, respectively [8]. For structural polymeric adhesives, moisture ingress is seldom the dominant factor that affects durability. A more important issue is how the moisture influences the adhesiveadherend interface region because of possible preferential accumulation of moisture at the joint interface resulting in loss of adhesion $[9,10]$.

Among a number of encapsulant materials for photovoltaic modules, ethylene-vinyl acetate (EVA) copolymer has been the one most commonly used since the mid-1980s. The commercial products of EVA have been found to fairly easily delaminate from glass substrates upon prolonged immersion in an $85^{\circ} \mathrm{C}$ water bath [11] or exposure to damp-heat, as observed in our laboratories. To improve the adhesion strength of adhesives against moisture-induced degradation, surface priming and use of alternative non-EVA adhesives, along with adequate substrate cleaning to reduce the surface contamination, are among a number of approaches that can be taken [11,12]. For example, Tucker investigated adhesion of two non-EVA polymers (CPVC and PMMA) on glass and compared the effectiveness of two silanes in enhancing EVA's long-term adhesion durability against damp-heat exposure, but with limited success [13]. The key concepts in formulating the primer solutions in this work were to use mixed silanes to introduce higher degrees of (1) surface hydrophobicity to exclude water molecules from the interfacial regions, (2) siloxane bonding density at the glass/EVA interface, and/or (3) cross-linking extent between the interfacial silanes and the EVA. Custom-formulated EVA and non-EVA polymers were also studied.

\section{EXPERIMENTAL}

The primer formulations consisted of various combinations of silane-based coupling agents at a $2 \%$ 
total volumetric concentration in $\mathrm{pH}=5.0,95: 5(\mathrm{v} / \mathrm{v})$ ethanol/ $/ \mathrm{H}_{2} \mathrm{O}$ mixture [14]. Table 1 shows the types of silane coupling agents and their interfacial functionality or purposes being studied. Table 2 lists the silane combinations of primer formulations used for the samples, but the exact concentration ratios of several were not indicated for proprietary reasons. Commercial low-iron, soda lime glass plates, AFG Krystal $\mathrm{Klear}^{\circledR}, 3.2 \mathrm{~mm}$ (1/8") thick at a size of $10 \mathrm{~cm} \times 10 \mathrm{~cm}$ (4" $\times 4$ "), were used. To ensure good silanization, the glass plates were thoroughly cleaned by first cleaning with diluted Liqui-Nox ${ }^{\circledR}$ for 15 min in a ultrasonicator, followed by soaking for about $30 \mathrm{~min}$ each in $1: 1(\mathrm{v} / \mathrm{v})$ methanol/ $\mathrm{HCl}$ and then in concentrated $\mathrm{H}_{2} \mathrm{SO}_{4}$; this was followed by rinsing with copious deionized $\mathrm{H}_{2} \mathrm{O}$ between and after acid soaking [15]. The cleaned glass surface gave an average contact angle of $\sim 4.5^{\circ}$ for water droplets (versus $\sim 52.2^{\circ}$ for the plates cleaned by the IPA-then-Billco $79 A^{\circledR}$ scrubbing method used by some PV manufacturers). Priming was conducted by immersing the glass plates in the primer solutions for 2 min followed by brief rinsing with ethanol. The primed glass plates were then treated at $\sim 93^{\circ}-97^{\circ} \mathrm{C}$ in a preheated oven for $10-12$ min. A commercial fast-cure EVA15295P/UF (0.46 mm thick), manufactured by Specialized Technology Resources (STR), was used for most sample laminations to the non-tinned glass surface side. Some customformulated, self-primed EVA and PMG formulations were also included in the test matrix. The PMG was an ethylene copolymer of methylacrylate containing glycidyl methacrylate. A total of 32 laminates were prepared with a common configuration of TPE/encapsulant/glass. The gel contents of the fast-cured EVA-15295, custom-formulated EVA, and PMG were analyzed using tetrahydrofuran extraction to be $90 \%-92 \%, 84 \%-86 \%$, and $52 \%-64 \%$, respectively. Damp-heat exposures were conducted in a Blue M, Model AC-7602HB chamber. The adhesion strength of the candidate encapsulants to the glass substrate was measured periodically using an Instron Model 5500 system with a 90-degree pull [16] and a crosshead speed of $10 \mathrm{~mm} / \mathrm{min}$. Typically, a 4-h dry-out was allowed before the peel tests were conducted.

Table 1. Silanes and their Interfacial Application Purposes

\begin{tabular}{|c|c|}
\hline Silane ID/Functional Group & Interfacial Functionality or Purpose \\
\hline Z-6030 ${ }^{(}$, Methacrylate- & Cross-linking \\
\hline Z-6032 ${ }^{\circledR}$, Vinylbenzyl- & Cross-linking and hydrophobicity \\
\hline Vinyl-, Epoxy- & Cross-linking and hydrophobicity \\
\hline Dipodal, Polysiloxane & Cross-linking and siloxane-concentration enhancing \\
\hline Amino-, Diamino- & Cross-linking and catalytic; but can be hydrophilic \\
\hline Fluoro-, Isobutyl, Phenyl- & Hydrophobicity \\
\hline
\end{tabular}

Table 2. Ranking Order of Primer Formulations and Self-Primed Encapsulants based on Time-Averaged Peel Strength as a Function of Damp-Heat Exposure

\begin{tabular}{|c|c|c|c|c|c|c|c|}
\hline $\begin{array}{l}\text { Sample } \\
\text { ID }\end{array}$ & $\begin{array}{l}\text { Base } \\
\text { Silane }\end{array}$ & $\begin{array}{c}\text { Silane } \\
\text { \#2 }\end{array}$ & $\begin{array}{c}\text { Silane } \\
\# 3\end{array}$ & $\begin{array}{l}\text { Init. PS } \\
\text { (N/mm) }\end{array}$ & $\begin{array}{l}\text { TAPS }^{1} \\
\left(\mathrm{~N} / \mathrm{mm}^{2}\right)\end{array}$ & $\begin{array}{l}\Delta \mathrm{PS}^{2} \\
(\mathrm{~N} / \mathrm{mm})\end{array}$ & $\begin{array}{l}\text { Rank } \\
\text { Order }\end{array}$ \\
\hline PMG-K, D6-1 ${ }^{3}$ & Z-6030 & Epoxy- & (Self-Primed $\left.^{4}\right)$ & 9.50 & 9.62 & 2.86 & 1 \\
\hline Z6030-J ${ }^{3}$ & Z-6030 & Fluoro- & Dipodal & 9.75 & 9.56 & 2.79 & 2 \\
\hline Z6030-C & Z-6030 & Vinyl- & N/A & 10.25 & 9.32 & 2.56 & 3 \\
\hline$Z 6032-B^{3}$ & Z-6032 & Dipodal & Amino- & 9.00 & 9.27 & 2.51 & 4 \\
\hline$Z 6032-A^{3}$ & Z-6032 & Vinyl- & Amino- & 11.50 & 9.15 & 2.39 & 5 \\
\hline Z6030-E & Z-6030 & Fluoro- & $\mathrm{N} / \mathrm{A}$ & 9.50 & 8.83 & 2.07 & 7 \\
\hline Z6030-L & Z-6030 & Phenyl- & $N / A$ & 11.00 & 8.72 & 1.96 & 8 \\
\hline Z6030-M & Z-6030 & Phenyl- & Diamino- & 11.00 & 8.69 & 1.93 & 9 \\
\hline Z6030-G & Z-6030 & Fluoro- & Amino- & 10.50 & 8.66 & 1.90 & 10 \\
\hline$Z 6030-I^{3}$ & Z-6030 & Epoxy- & Amino- & 10.50 & 8.40 & 1.64 & 13 \\
\hline Z6030-D & Z-6030 & Dipodal & $\mathrm{N} / \mathrm{A}$ & 10.00 & 8.38 & 1.62 & 15 \\
\hline Z6030-K & Z-6030 & Diamino- & $\mathrm{N} / \mathrm{A}$ & 11.00 & 8.21 & 1.45 & 16 \\
\hline Z6032-C & Z-6032 & Vinyl- & Diamino- & 10.00 & 7.83 & 1.07 & 18 \\
\hline Z6030-S & Z-6030 & Phenyl- & Dipodal & 11.00 & 7.59 & 0.83 & 19 \\
\hline Z6030-A & Z-6030 & $\mathrm{N} / \mathrm{A}$ & $\mathrm{N} / \mathrm{A}$ & 9.50 & 7.58 & 0.82 & 20 \\
\hline Z6030-B & Z-6030 & Amino- & $\mathrm{N} / \mathrm{A}$ & 11.50 & 6.93 & 0.17 & 24 \\
\hline EVA-B, F/E-2 & Z-6030 & Polysiloxane & (Self-Primed $^{4}$ ) & 10.25 & 6.93 & 0.17 & 25 \\
\hline Control & Z-6030 & & $\left(\right.$ Self-Primed $\left.^{4}\right)$ & 6.76 & 6.76 & 0.00 & 26 \\
\hline
\end{tabular}

\section{RESULTS AND DISCUSSION}

In the commercial "self-primed" EVA formulations [13], a functional silane coupling agent such as Z6030 ${ }^{\circledR}$
(Dow Corning) is commonly used to enhance EVA adhesion strength to glass substrates by forming $\mathrm{Si}-\mathrm{O}-\mathrm{Si}$ siloxane bonds with the hydroxyl groups on the glass surface via a condensation reaction. Without the silane, 
the EVA adhesion strength would be about six to ten times weaker $[11,13]$. However, in the presence of moisture and elevated temperatures, the $\mathrm{Si}-\mathrm{O}-\mathrm{Si}$ bonding is reversible by hydrolysis. A possible solution to the problem is to reduce the "free space" at the interfacial regions to exclude water molecules from accumulating at the interfacial regions. This was achieved by using silanes such as fluoro-, dipodal, phenyl-, and vinyl- (Table 1) for a greater degree of hydrophobicity and density of siloxane bonding between the silane and glass in formulating the primer solutions. To increase the cross-linking between the silane and EVA, functional silanes such as methacrylate (Z-6030), vinylbenzyl (Z-6032), and vinyl were used. Amino silanes were used primarily as catalysts. Similar approaches of using mixed silanes for various polymer materials are reported in the literature [17-20].

Figure 1 compares the peel strength (PS) data for six samples laminated with the glass substrates primed with Z-6030-based primer solutions with a unprimed-glass "control" as a function of damp heat exposure time to 500 h. Figure 2 shows the peel strength plot for three samples laminated with the glass substrates primed with Z-6032based primer solutions, one custom-formulated EVA-B, and two PMG-K samples. Upon longer exposures to $\sim 750-775 \mathrm{~h}$, the TPE film was largely weakened or degraded, with interlayer delamination of Tedlar/PET (TP) from EVA (E). This delamination prevented reliable peel strength measurements from being made and shown in both figures. As seen in Fig. 1, all the samples with Z6030-based primed glass substrates exhibit higher initial peel strength than that of the control with unprimed-glass substrate. Their resistance to damp-heat exposure is also generally better than the control, although two showed a worse trend at $500 \mathrm{~h}$. Similar results are observed in Fig. 2 for samples with Z-6032-base primed glass substrates. For the EVA-B that was custom-formulated with Z-6030 and a $\mathrm{H}$-terminated polysiloxane (H-PDMS) and laminated to the unprimed-glass substrate, a high initial peel strength was followed by rapid deterioration of adhesion strength after being exposed to damp heat. However, in a separate study, the H-PDMS catalytically primed on glass substrates had shown very good resistance to hydrolytic

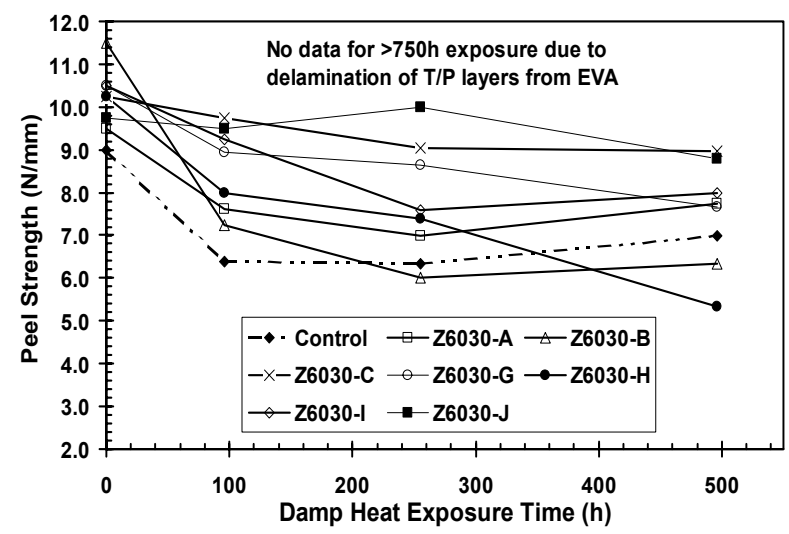

Fig. 1. Peel strength measured for eight TPE/EVA/ glass laminates exposed to damp heat for $\sim 500 \mathrm{~h}$.

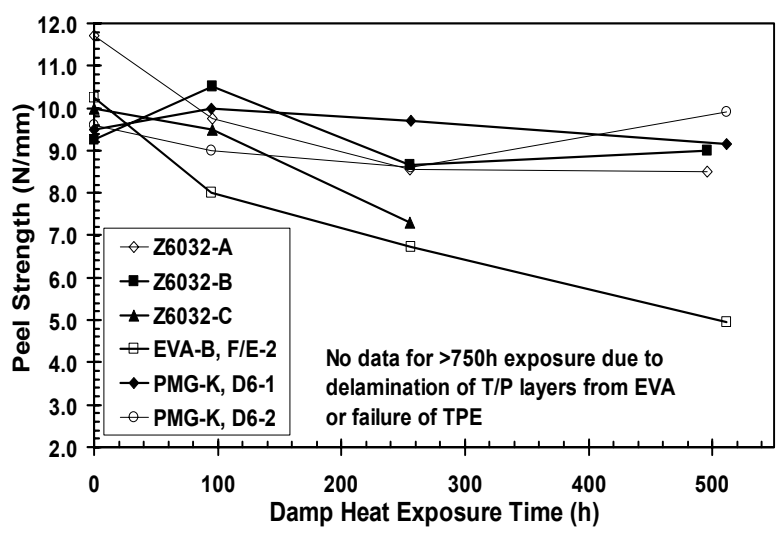

Fig. 2. Peel strength measured for six TPE/EVA (or $P M G$ )/glass laminates exposed to damp heat for $500 \mathrm{~h}$

loss when soaked in an $85^{\circ} \mathrm{C}$ water bath. The presence of $\mathrm{H}$-PDMS polysiloxane was observed to cause a great degree of difficulty for the EVA-B and PMG-B formulation to be extruded into films. For PMG-K formulated with Z6030 and a second epoxy-type silane, film extrusion problems were not observed, and the loss of adhesion strength during damp-heat exposure was relatively small, as seen in Fig. 2.

To evaluate and compare the effectiveness of the various primer formulations on enhancing EVA adhesion during damp-heat exposures, a statistical analysis of comparative time-averaged performance (i.e., "TAPS" in Table 2) was employed. A test criterion, w, was defined, which depends on the estimated standard deviation of the acquired data and the percentiles of the studentized range, $\mathrm{q}[21]$.

$$
w=\frac{q_{1-\alpha} \cdot \sigma}{\sqrt{n}}
$$

For a confidence interval of $99 \%, w$ was determined to be $0.94 \mathrm{~N} / \mathrm{mm}$ for the set of 32 samples. If the difference in TAPS between two samples is greater than $w$, then we conclude with $99 \%$ confidence that a primer produced a statistically significant improvement in peel strength between the two samples. The results of calculated TAPS, their difference from the control $(\triangle P S)$, and the ranking order are given in Table 2 for 18 of the 32 samples and their (unduplicated) primer silane combinations. The six samples that performed poorer than the control are not shown. A comparison of the $\Delta \mathrm{PS}$ indicates that primer formulations Z-6030-A, B, S, and EVA-B F/E-2, with $\triangle P S$ in the $0.17-0.83$ range $(<1 \mathrm{w}$, rank order from 19 to 25), offer statistically insignificant improvements versus the unprimed control. For the other samples that show $\triangle \mathrm{PS}$ in the 1.07-1.96 range (rank order from 8 to 18), the largest spread, 2.80(Z6030-L) $1.62(Z 6032-C)=0.89$, is less than $w=0.94$, further suggesting the adhesion strength improvements provided by these primer solutions are statistically comparable. For those primer formulations ranking from 2 to 7 in Table 2 with $2.07<\Delta \mathrm{PS}<2.79$, the improvements on the adhesion strength during damp-heat exposure are 
statistically more significant. Peeling could not be initiated for the four samples, Z-6030-I and J and Z-6032-A and B, before and after damp-heat exposure because of strong EVA adhesion. The peel strength results thus obtained are less accurate for these four samples. However, three of them, excluding Z6030-I, rank among the top five in TAPS values. For self-primed PMG-K D6-1, which ranks No. 1, peeling tests could not be ever truly performed even after $750 \mathrm{~h}$ exposure. The enhanced adhesion is attributed to the presence of functional groups of methacrylate and glycidyl methacrylate in the PMG that provide greater bonding than EVA to the glass surface, in addition to the siloxane bonding from Z-6030 and epoxy silane in the formulation. As evaluated from the silane components of primer formulations for the six highest TAPS, the mechanisms responsible for enhanced EVA adhesion during damp-heat exposure are attributed to (1) an increase in the siloxane bonding density via the smaller silane molecules of cross-linking vinyl or dipodal silanes, (2) a presence of hydrophobic fluorosilane, (3) a dominant use of Z6032 vinylbenzyl silane (with vinyl and hydrophobic benzyl), and/or (4) a presence of lowconcentration aminosilane serving as a catalyst. These factors have worked synergistically as designed to increase the interfacial hydrophobicity and cross-linking density with the EVA. These results are consistent with those reported in the literature [17-19]. However, the presence of "additional" Z-6030 on the glass surface by priming with Z6030-A (see Table 2) provided only little improvement. A high concentration of amino silane alone (e.g., 25\%) was found adverse to reduce adhesion strength by possibly causing the interfacial regions to become relatively more hydrophilic.

\section{CONCLUSIONS}

Several primer formulations of mixed silanes are identified from peel tests to enhance the adhesion strength of EVA/glass laminates during prolonged dampheat exposure. A synergistic increase in the interfacial hydrophobicity, siloxane density, and cross-linking density by the use of carefully selected silane combinations are the key attributes to the improvement. Specifically, the carefully selected silane combinations that provided the most enhanced EVA adhesion consist of (1) an increase in the siloxane bonding density via the smaller silane molecules of cross-linking vinyl or dipodal silanes, (2) a presence of hydrophobic fluorosilane, (3) a dominant use of vinylbenzyl silane (with vinyl and hydrophobic benzyl), and/or (4) a presence of low-concentration aminosilane serving as a catalyst. Self-primed (non-EVA) PMG appears to be very promising for offering high waterresistant potential. For convenience in practical use, the best-performing primer formulations developed in this work have been formulated into EVA encapsulant films for damp-heat tests to further verify their performance.

\section{ACKNOWLEDGEMENT}

This work was performed at NREL under U.S. Department of Energy Contract No. DE-AC36-99G010337.

\section{REFERENCES}

[1] E.L. Meyer and E.E. van Dyk, "Assessing the Reliability and Degradation of Photovoltaic Module Performance Parameters," IEEE Trans. Reliability, 53, 2004, pp. 83-92.

[2] T.J. McMahon, "Accelerated Testing and Failure of Thin Film PV Modules," Prog. Photovolt: Res. Appl., 12, 2004, pp. 235-248.

[3] Moisture Ingress and High Voltage Isolation Workshop, March 9-11, 2001, Golden, CO.

[4] Proceedings of First Thin Film Module Reliability National Team Meeting, Sept. 4-5, 2002, Golden, CO.

[5] Proceedings of Second Thin Film Module Reliability National Team Meeting, Feb. 27-28, 2003, Cocoa, FL.

[6] Proceedings of Third Thin Film Reliability National Team Meeting, Sept. 18-19, 2003, Albuquerque, NM.

[7] Proceedings of Fourth Thin Film Reliability National Team Meeting, June 23-24, 2004, Golden, CO.

[8] "How Moisture Affects Adhesive and Sealant Joints Part I," Technical article of SpecialChem4Adhesives website, July 16, 2003.

[9] "Polymer Permeability," J. Comyn ed., Chaps. 1, 2, and 5, Elsevier Applied Science, New York, 1986.

[10] "Improving the Moisture Resistance of Adhesives and Sealants - part II," Technical article of SpecialChem4 Adhesives website, July 23, 2003.

[11] F.J. Pern, unpublished results.

[12] "Cleaning Processes for Improving Adhesion," Technical article of SpecialChem4Adhesives website, July 30, 2003.

[13] R.T. Tucker, "Primers and Adhesion," presented in ref. 4.

[14] "Silane Coupling Agents: Connecting Across Boundaries," Product brochure of Gelest Inc., 2003, "Applying Silanes," pp. 17.

[15] J.J. Cras, C.A. Rowe-Taitt, D.A. Nivens, and F.S. Ligler, "Comparison of Chemical Cleaning Methods of Glass in Preparation for Silanization," Biosensors \& Bioelectronics, 14, 1999, pp. 683-688.

[16] F.J. Pern and S.H. Glick, "Adhesion Strength Study of EVA Encapsulants on Glass Substrates," Proceedings of NCPV and Solar Program Review Meeting, March 24-26, 2003, Denver, CO.

[17] "Silane Coupling Agents," E. P. Plueddemann, Plenum Press, New York, 1982.

[18] P.G. Page and E.P. Plueddemann, "Methods for Improving the Performance of Silane Coupling Agents," in "Silanes and Other Coupling Agents," K.L. Mittal ed., VSP, 1992, pp. 105-116.

[19] R.G. Craig and E.R. Dootz, "Effect of Mixed Silanes on the Hydrolytic Stability of Composites," J. Oral Rehabilitation, 23, 1996, pp. 751-756.

[20] N. Nishiyama, T. Ishizaki, K. Horie, M. Tomari, and M. Someya, "Novel Polyfunctional Silanes for Improved Hydrolytic Stability at the Polymer-Silica Interface," J. Biomed. Mat. Research, 25, 1991, pp. 213-221.

[21] "Experimental Statistics," Handbook 91, U.S. Department of Commerce, NBS, 1963, pp. 3-40 - 342. 


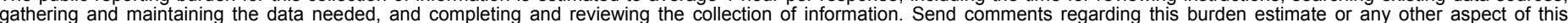

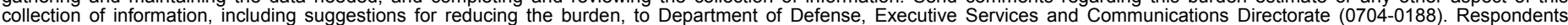

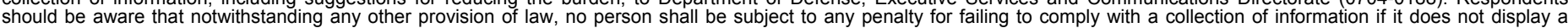

should be aware that notwithstanding

PLEASE DO NOT RETURN YOUR FORM TO THE ABOVE ORGANIZATION.
1. REPORT DATE (DD-MM-YYYY)
February 2005
4. TITLE AND SUBTITLE
Enhanced Adhesion of EVA Laminates to Primed Glass Substrates
Subjected to Damp Heat Exposure

3. DATES COVERED (From - To)

3-7 January 2005

5a. CONTRACT NUMBER

DE-AC36-99-G010337

5b. GRANT NUMBER

5c. PROGRAM ELEMENT NUMBER

5d. PROJECT NUMBER

NREL/CP-520-37391

5e. TASK NUMBER

PVB57201

5f. WORK UNIT NUMBER
7. PERFORMING ORGANIZATION NAME(S) AND ADDRESS(ES)

National Renewable Energy Laboratory

1617 Cole Blvd.

Golden, CO 80401-3393
8. PERFORMING ORGANIZATION REPORT NUMBER

NREL/CP-520-37391

9. SPONSORING/MONITORING AGENCY NAME(S) AND ADDRESS(ES)

10. SPONSOR/MONITOR'S ACRONYM(S)

NREL

11. SPONSORING/MONITORING AGENCY REPORT NUMBER

12. DISTRIBUTION AVAILABILITY STATEMENT

National Technical Information Service

U.S. Department of Commerce

5285 Port Royal Road

Springfield, VA 22161

13. SUPPLEMENTARY NOTES

\section{ABSTRACT (Maximum 200 Words)}

We investigated the effectiveness of glass-surface priming to promote enhanced adhesion of EVA laminates during damp-heat exposure at $85^{\circ} \mathrm{C}$ and $85 \%$ relative humidity. The primary objective was to develop advanced encapsulant formulations by incorporation of various primer formulations that exhibit improved adhesion during damp-heat exposure. Several primer formulations were identified that greatly enhanced the EVA adhesion strength, including to the extent that peeling could not be initiated, even for the laminates of the glass substrate/fast-cure EVA15295P/TPE backsheet (a Tedlar/ polyester/EVA tri-laminate) that were exposed in a damp-heat test chamber for more than $750 \mathrm{~h}$. The results show that a synergistic increase in the interfacial hydrophobicity, siloxane density, and cross-linking density are the key attributes to the improvement in the EVA adhesion strength.

\section{SUBJECT TERMS}

PV; ethylene-vinyl acetate (EVA); glass surface priming; enhanced adhesion; damp-heat exposure;

\begin{tabular}{|c|c|c|}
\hline $\begin{array}{l}\text { a. REPORT } \\
\text { Unclassified }\end{array}$ & $\begin{array}{l}\text { b. ABSTRACT } \\
\text { Unclassified }\end{array}$ & $\begin{array}{l}\text { c. THIS PAGE } \\
\text { Unclassified }\end{array}$ \\
\hline
\end{tabular}

\begin{tabular}{l|l|l} 
17. LIMITATION & 18. NUMBER & NUMA \\
OF ABSTRACT & OF PAGES \\
UL &
\end{tabular}

19a. NAME OF RESPONSIBLE PERSON

19b. TELEPHONE NUMBER (Include area code) 